Surface Science 104 (1981) 181-198

North-Holland Publishing Company

\title{
ADSORPTION AND DECOMPOSITION OF HNCO ON Cu(111) SURFACE STUDIED BY AUGER ELECTRON, ELECTRON ENERGY LOSS AND THERMAL DESORPTION SPECTROSCOPY
}

\author{
F. SOLYMOSI and J. KISS \\ Reaction Kinetics Research Group, The University, P.O. Box 105, H-6701 Szeged, Hungary
}

Received 25 June 1980; accepted for publication 13 October 1980

\begin{abstract}
No detectable adsorbed species were observed after exposure of $\mathrm{HNCO}$ to a clean $\mathrm{Cu}(111)$ surface at $300 \mathrm{~K}$. The presence of adsorbed oxygen, however, exerted a dramatic influence on the adsorptive properties of this surface and caused the dissociative adsorption of HNCO with concomitant release of water. The adsorption of $\mathrm{HNCO}$ at $300 \mathrm{~K}$ produced two new strong losses at 10.4 and $13.5 \mathrm{eV}$ in electron energy loss spectra, which were not observed during the adsorption of either $\mathrm{CO}$ or atomic $\mathrm{N}$. These loses can be attributed to surface $\mathrm{NCO}$ on $\mathrm{Cu}(111)$. The surface isocyanate was stable up to $400 \mathrm{~K}$. The decomposition in the adsorbed phase began with the evolution of $\mathrm{CO}_{2}$. The desorption of nitrogen started at $700 \mathrm{~K}$. Above $800 \mathrm{~K}$, the formation of $\mathrm{C}_{2} \mathrm{~N}_{2}$ was observed. The characteristics of the $\mathrm{CO}_{2}$ formation and the ratios of the products sensitively depended on the amount of preadsorbed oxygen. No HNCO was desorbed as such, and neither $\mathrm{NCO}$ nor $(\mathrm{NCO})_{2}$ were detected during the desorption. From the comparison of adsorption and desorption behaviours of $\mathrm{HNCO}, \mathrm{N}, \mathrm{CO}$ and $\mathrm{CO}_{2}$ on copper surfaces it was concluded that $\mathrm{NCO}$ exists as such on a $\mathrm{Cu}(111)$ surface at $300 \mathrm{~K}$. The interaction of HNCO with oxygen covered $\mathrm{Cu}(111)$ surface and the reactions of surface NCO with adsorbed oxygen are discussed in detail.
\end{abstract}

\section{Introduction}

This study is part of our program relating to a better understanding of the surface processes occurring during the metal-catalyzed $\mathrm{NO}+\mathrm{CO}$ reactions, which is of great technological importance. Detailed infrared spectroscopic measurements in the recent past revealed that during the $\mathrm{NO}+\mathrm{CO}$ reaction on supported metals an isocyanate (NCO) surface species is formed [1-3]. This reacts rapidly with water to yield ammonia [4], which strongly supports the assumption that surface NCO is primarily responsible for the undesired formation of $\mathrm{NH}_{3}$ during automobile exhaust catalysis.

Although the infrared spectroscopic measurements provided much information on the formation of NCO species on different supported metals, not much was revealed as to the nature of the bonding between the $\mathrm{NCO}$ and the metal, or the reactivity of the NCO species. The reason is that the oxidic supports drastically influence the reactivity of $\mathrm{NCO}$ formed on the metal [3-5]. 
The primary aim of this work is to establish details of the interaction between $\mathrm{NCO}$ and the $\mathrm{Cu}(111)$ surface. As it is not possible to produce surface isocyanate via the $\mathrm{NO}+\mathrm{CO}$ reaction at low pressures, we tried to circumvent this problem by using isocyanic acid, $\mathrm{HNCO}$, directly as adsorbing species.

\section{Experimental}

Experiments were performed in a stainless steel UHV chamber equipped with several gas inlets, a single-pass cylindrical mirror analyzer (PHI) for Auger electron spectroscopy, a 3-grid retarding field analyzer (VG) for low-energy electron diffraction and a quadrupole mass analyzer (VG) to monitor gas-phase compositions. The vacuum system was evacuated with ion pumps and a titanium getter. A base pressure of $7 \times 10^{-11}$ Torr was routinely obtainable in this chamber.

Auger electrons were generated using electron excitation and measured in their usual first derivative mode. Auger spectra were taken with $3 \mathrm{~V}$ peak-to-peak modulation, $2.5 \mathrm{kV}$ of incident energy, $1-10 \mu \mathrm{A}$ of beam current and a sweep rate of $3 \mathrm{~V} / \mathrm{s}$. The beam area was about $0.4 \mathrm{~mm}^{2}$.

Electron energy loss spectra were taken in $N(E)$ and $\mathrm{d} N(E) / \mathrm{d} E$ form at normal incidence of the primary beam, using the Auger optics as a single-pass CMA analyzer. The primary energy used was $20-125 \mathrm{eV}$. The beam current varied from 0.2 to $1.0 \mu \mathrm{A}$. A modulation voltage was $200 \mathrm{mV}$ ptp.

The oriented disk-shaped crystal (diameter $6 \mathrm{~mm}$, thickness $1.5 \mathrm{~mm}$ ) was obtained from Materials Research Corporation. The sample was mechanically polished and was mounted in a copper sample holder. The sample was heated from the rear by the radiation of a tungsten filament. The temperature was measured with a chromel-alumel thermocouple spot-welded to the edge of the crystal. The surface was cleaned by cycles of sputtering (typically $600 \mathrm{eV} \mathrm{Ar}^{+}, 3 \mu \mathrm{A}$ for $10-30 \mathrm{~min}$ ) and annealing at $970 \mathrm{~K}$ for some minutes.

$\mathrm{HNCO}$ was prepared by the reaction of saturated aqueous $\mathrm{KNCO}$ solution with $95 \% \mathrm{H}_{3} \mathrm{PO}_{4}$ at $300 \mathrm{~K}$ [6]. The product was purified several times by bulb-to-bulb distillation under HV and UHV conditions. HNCO was introduced into the chamber from an auxilary vacuum system pumped by a small $(8 \mathrm{l} / \mathrm{s})$ ion pump through a stainless steel tube with a diameter of $0.8 \mathrm{~mm}$. The crystal face was positioned about $0.5 \mathrm{~cm}$ in front of the effusion hole.

\section{Results}

\subsection{Adsorption on a clean $\mathrm{Cu}(111)$ surface}

Exposure of the clean $\mathrm{Cu}(111)$ surface to $\mathrm{HNCO}$ (up to $1200 \mathrm{~L}$ ) at $300 \mathrm{~K}$ resulted in no detectable change in the Auger spectrum, and we could not identify 


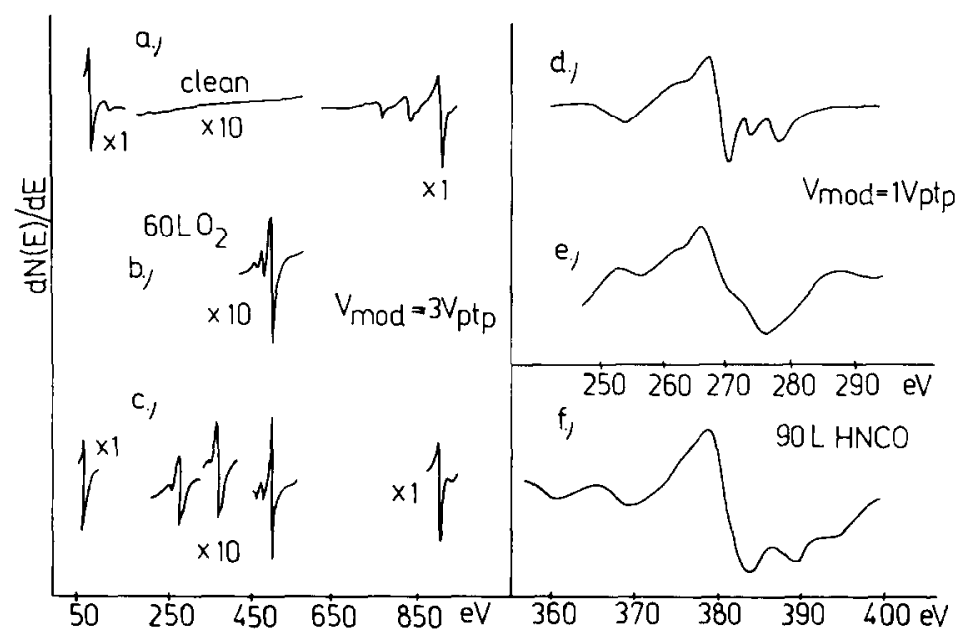

Fig. 1. Auger spectra of the $\mathrm{Cu}(111)$ surface taken: (a) with clean surface and after exposure to $100 \mathrm{~L}$ HNCO at $300 \mathrm{~K}$; (b) after exposure to $60 \mathrm{~L} \mathrm{O} \mathrm{O}_{2}(\theta \approx 0.17)$ at $300 \mathrm{~K}$; (c) after exposure of the oxygen covered surface $(\theta \approx 0.17)$ to $90 \mathrm{~L} \mathrm{HNCO}$ at $300 \mathrm{~K}$; (d) carbon Auger line shape after HNCO exposure; (e) carbon Auger line shape produced by the dissociation of $\mathrm{CO}$ due to electron bombardment; (f) N Auger line shape after HNCO exposure.

any desorbing products on heating the sample up to $1020 \mathrm{~K}$ (fig. 1).

In agreement with previous studies, no adsorption or disproportionation of $\mathrm{CO}$ on a clean $\mathrm{Cu}(111)$ surface was observed by Auger sectroscopy at $300 \mathrm{~K}$ (exposure $2 \times 10^{3} \mathrm{~L}$ ). No interaction was experienced between $\mathrm{CO}_{2}$ and a clean $\mathrm{Cu}(111)$ surface (exposure $1 \times 10^{3} \mathrm{~L}$ ).

\subsection{Adsorption of HNCO on an oxygen-covered surface, AES studies}

The adsorption of oxygen was performed at $300 \mathrm{~K}$. LEED patterns showed no extra spots, but an increase in the background intensity was observed. Fig. 2 shows the ratio $h_{\mathrm{O}} / h_{\mathrm{Cu}}$ of the oxygen $514 \mathrm{eV}$ to the copper $920 \mathrm{eV}$ peak-to-peak heights in the first derivative Auger spectra versus exposure of oxygen. Higher degrees of coverage were obtained in the pressure range $10^{-5}-10^{-6}$ Torr. The absolute coverage of oxygen was calculated by using the relationship found by Bootsma et al. [7] between the ratio $h_{\mathrm{O}} / h_{\mathrm{Cu}}$ in the Auger spectra and $\delta \Delta$ (ellipsometry), as well as between $\delta \Delta$ and the oxygen coverage. In this calculation one takes into account that the adsorption of oxygen on the $\mathrm{Cu}(110)$ surface leads to a $(2 \times 1)$ LEED pattern, which means that the ratio of $\mathrm{O}$ atoms $/ \mathrm{Cu}$ surface atom equals 0.5 . It is also assumed that the $\mathrm{Cu} 920 \mathrm{eV}$ Auger signals are cqual for $\mathrm{Cu}(111)$ and $\mathrm{Cu}(110)$.

Exposure of the oxygenated surface $(\theta \approx 0.17)$ to $\mathrm{HNCO}$ at $300 \mathrm{~K}$ resulted in the appearance of the $\mathrm{N}$ and $\mathrm{C} \mathrm{KLL}$ signals at 384 and $271 \mathrm{eV}$ and a slight increase 


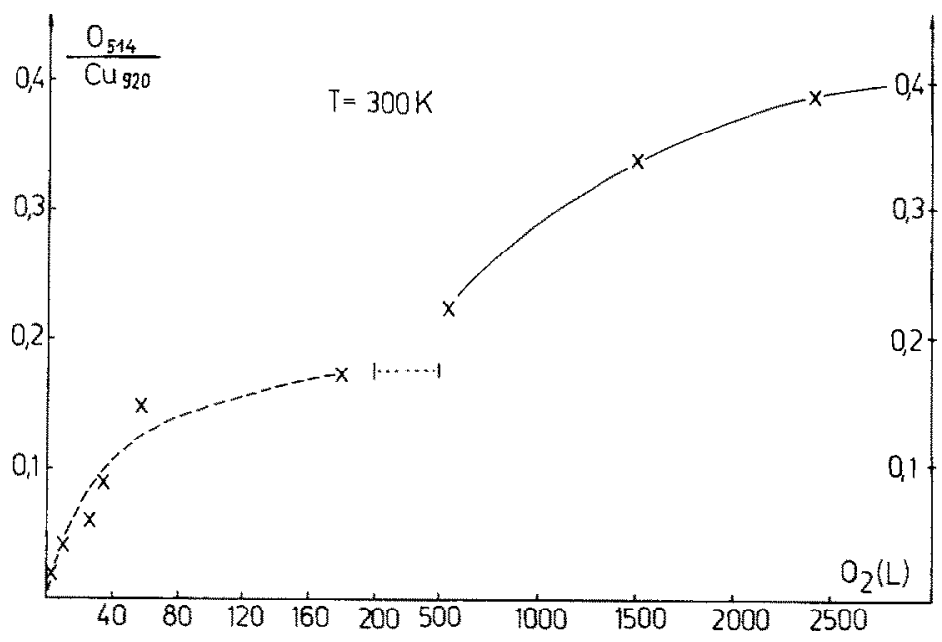

Fig. 2. Ratio of the $\mathrm{O} 514 \mathrm{eV}$ to $\mathrm{Cu} 920 \mathrm{eV}$ peak versus exposure of oxygen to a clean $\mathrm{Cu}(111)$ surface.

of the $\mathrm{O}$ signal at $514 \mathrm{eV}$ (fig. 1). At the same time, mass spectrometric analysis of the gas phase indicated water formation. No other products were identified, however, even when the admission of $\mathrm{HNCO}$ onto the sample was performed in the most favourable position, i.e. in front $(\sim 10 \mathrm{~mm})$ of the analyzer head of the MS. The adsorption of HNCO did not change the LEED pattern of oxygen covered surface.

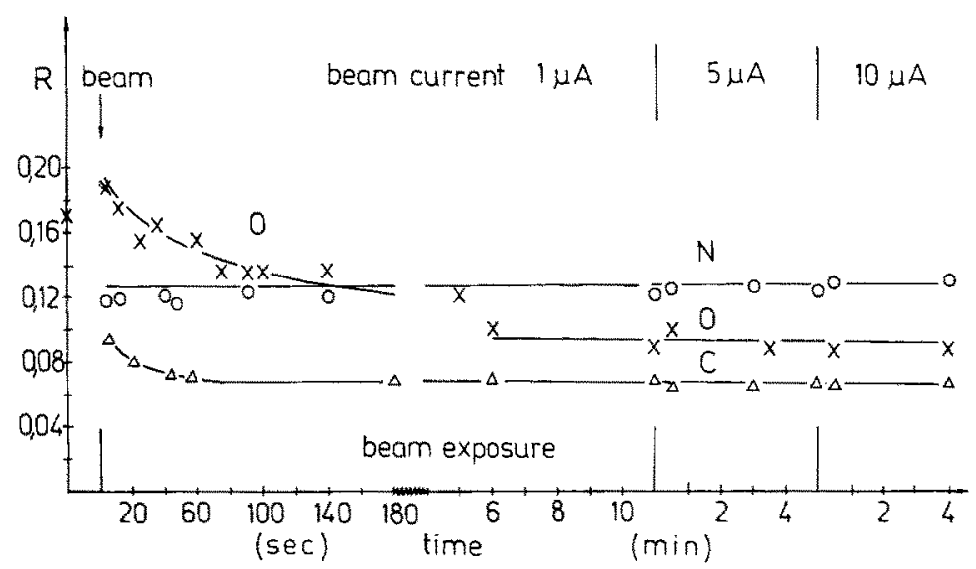

Fig. 3. The effect of the beam current and beam exposition on the relative intensities of $\mathrm{N}, \mathrm{O}$ and $C$ Auger signals. The oxygen covered $(\theta \approx 0.17) \mathrm{Cu}(111)$ surface was exposed to $90 \mathrm{~L}$ $\mathrm{HNCO}$ at $300 \mathrm{~K}$. Auger beam energy $2.5 \mathrm{kV}\left(R=\mathrm{O}_{514} / \mathrm{Cu}_{920}(\mathrm{X}) ; \mathrm{N}_{384} / \mathrm{Cu}_{920}(\mathrm{O}) ; \mathrm{C}_{271} /\right.$ $\mathrm{Cu}_{920}(\Delta)$. 
As the $\mathrm{C}-\mathrm{O}$ bond is very sensitive to an electron beam, detailed studies were performed to establish the effect of an electron beam on the adsorbed NCO. In order to detect the electron beam induced effect a $1 \mu \mathrm{A}, 2.5 \mathrm{keV}$ electron beam was initially used for Auger excitation. Even under these conditions a significant decrease could be observed in the relative intensity of $O$ signal with increasing exposure to the electron beam (fig. 3). With further increase of beam current, only a slight change occurred. When the first Auger spectrum was taken at high beam current $(\sim 10 \mu \mathrm{A})$ the final low $\mathrm{O}$ signal was obtained already at the first measurement.

Much less effect was detected in the carbon signal, and no decrease in the $\mathrm{N}$ signal was experienced even at high beam current (fig. 3).

In order to minimize the effect of the beam, the important signals were always taken first, and then the other part of the Auger spectrum.

We mention here that, in addition to the main $\mathrm{C}$ peak at $271 \mathrm{eV}$, two smaller ones appeared in the spectra about 3 and $7 \mathrm{eV}$ higher in energy (fig. 1). No such a feature was observed when surface $\mathrm{C}$ was produced by the dissociation of $\mathrm{CO}$ due

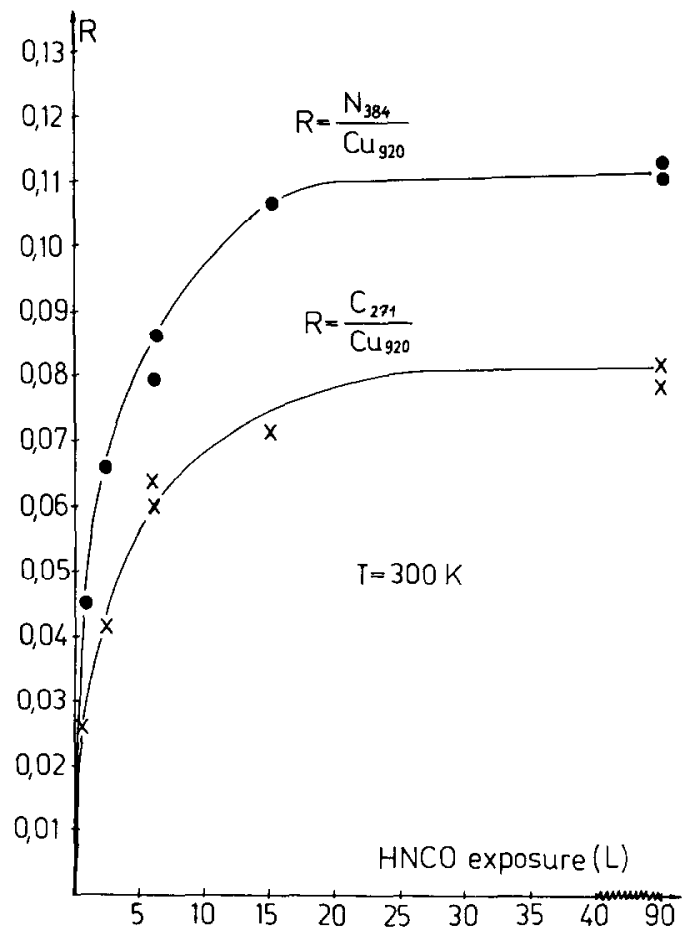

Fig. 4. The dependence of the relative $\mathrm{N}$ and $\mathrm{C}$ signals on the HNCO exposure. The surface was predosed with $60 \mathrm{~L} \mathrm{O}_{2}(\theta \approx 0.17)$ at $300 \mathrm{~K}$. 


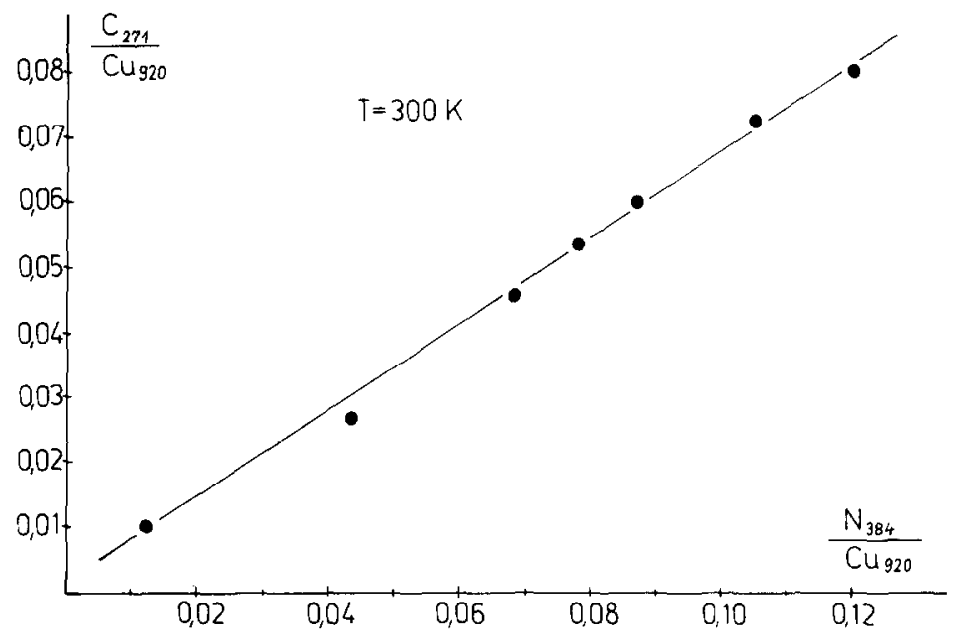

Fig. 5. The relative $C$ Auger signal versus relative $\mathrm{N}$ Auger signal on oxygen covered surface $(\theta \approx$ $0.17)$ at different $\mathrm{HNCO}$ exposures.

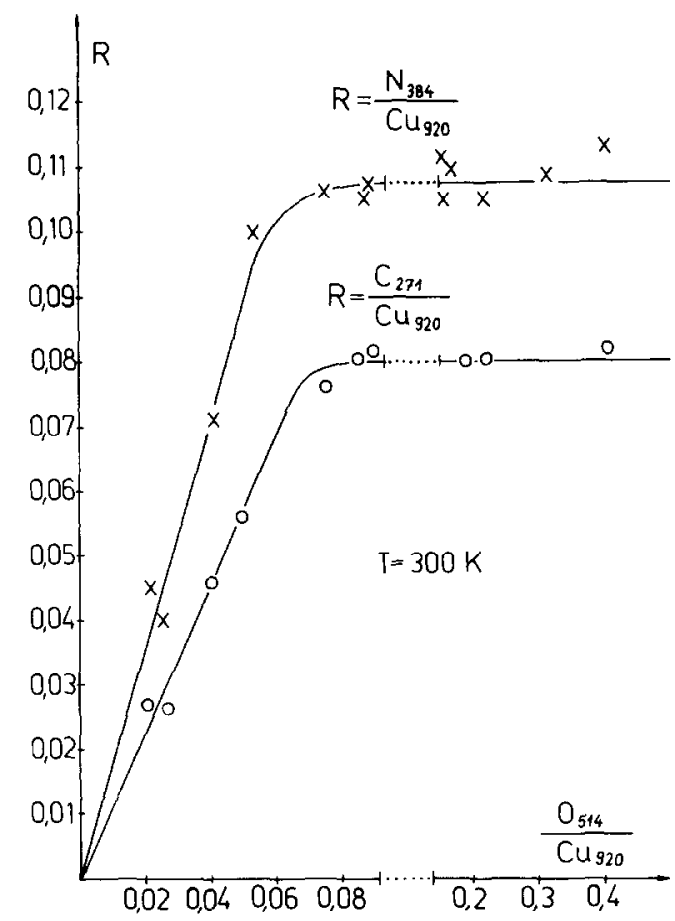

Fig. 6. The effect of oxygen coverage on the relative Auger signals of $\mathrm{N}$ and $\mathrm{C}$. The exposition of $\mathrm{HNCO}$ was $90 \mathrm{~L}$. 
to the electron bombardment (curve e of fig. 1). This results can very likely be attributed to the difference in the chemical environments of the adsorbed molecules which influences the Auger line shapes [8-10]. Similarly, two smaller peaks were observed about 5 and $10 \mathrm{eV}$ above, and about 15 and $23 \mathrm{eV}$ below the main peak of $\mathrm{N}(384 \mathrm{eV})$. Comparative studies are in progress in our laboratory to exploit the advantage of $\mathrm{NCO}$ as a complex molecule in establishing precisely the effect of the environment on the Auger line shapes of N, C and $\mathrm{O}$ atoms on copper and other metals.

In fig. 4 we have plotted the relative $\mathrm{N}$ and $\mathrm{C}$ signals against $\mathrm{HNCO}$ exposure. It can be seen that both signals reached constant values at 20-25 L HNCO exposure. When the relative $C$ signal was plotted against the relative $\mathrm{N}$ signal, we obtained a straight line (fig. 5).

Fig. 6 shows the effect of oxygen coverage on the adsorption of HNCO. In this case the exposure to $\mathrm{HNCO}$ was constant, at $90 \mathrm{~L}$. The $\mathrm{N}$ and $\mathrm{C}$ signals increased linearly with the surface concentration of oxygen up to the ratio $h_{\mathrm{O}} / h_{\mathrm{Cu}} \approx 0.06$, which corresponds to $\sim 0.05$ coverage. The highest values were reached at $\theta \approx 0.07$. Further increase of the $O$ coverage exerted no observable influence on the adsorption of $\mathrm{HNCO}$.

\subsection{Thermal desorption measurements}

Thermal desorption spectra were taken at a linear heating rate of $10 \mathrm{~K} \mathrm{~s}^{-1}$. The major signals were at $44 \mathrm{amu}\left(\mathrm{CO}_{2}\right), 28 \mathrm{amu}\left(\mathrm{CO}+\mathrm{N}_{2}\right)$ and $52 \mathrm{amu}\left(\mathrm{C}_{2} \mathrm{~N}_{2}\right)$ (fig. 7). Care was taken to try to detect signals due to $\mathrm{H}_{2}, \mathrm{NH}_{3}, \mathrm{HCN}, \mathrm{HNCO}, \mathrm{NCO},(\mathrm{NCO})_{2}$ and $\mathrm{H}_{2} \mathrm{O}$, without any positive results.

The evolution of carbon dioxide sensitively depended on the amount of preadsorbed oxygen. At very low oxygen coverage $\left(h_{\mathrm{O}} / h_{\mathrm{Cu}}=0.018\right)$ only one $\mathrm{CO}_{2}$ peak $\left(\alpha_{3}\right)$ was observed at $670 \mathrm{~K}$. At higher oxygen coverage $\left(h_{\mathrm{O}} / h_{\mathrm{Cu}}>0.10\right)$ the amounts of desorbed gases significantly increased. Carbon dioxide desorbed in two main stages, with a peak maximum at $463 \mathrm{~K}\left(\alpha_{1}\right)$ and $633 \mathrm{~K}\left(\alpha_{2}\right)$ at saturation. At $670 \mathrm{~K}$ only a shoulder was observed (fig. 7).

The desorption of nitrogen started always above $700 \mathrm{~K}$. In order to differentiate between $\mathrm{N}_{2}$ and $\mathrm{CO}$, the behaviour of the signal at $14 \mathrm{amu}\left(\mathrm{N}^{+}\right)$was compared with that at 28 amu. Calculation led us to conclude that the 28 amu signal is due to $\mathrm{N}_{2}$, and practically no contribution is made by $\mathrm{CO}$. $\Lambda \mathrm{t}$ higher temperatures, above $800 \mathrm{~K}$, the desorption of $\mathrm{C}_{2} \mathrm{~N}_{2}$ was observed. While the ratios of desorbed gases, $\mathrm{CO}_{2} / \mathrm{C}_{2} \mathrm{~N}_{2}$ and $\mathrm{N}_{2} / \mathrm{C}_{2} \mathrm{~N}_{2}$, increased with the oxygen coverage, the value of $\mathrm{CO}_{2} / \mathrm{N}_{2}$ remained unchanged (table 1 ).

In the subsequent measurements the oxygen coverage was kept constant $\left(h_{\mathrm{O}} /\right.$ $\left.h_{\mathrm{Cu}}=0.17\right)$ and the exposure of $\mathrm{HNCO}$ was varied. At a low exposure of $\mathrm{HNCO}$, only the low temperature $\mathrm{CO}_{2}$ peak $\left(\alpha_{1}\right)$ was observed $\left(T_{\max }=513 \mathrm{~K}\right)$. With the increase of $\mathrm{HNCO}$ exposure, $T_{\max }$ was shifted to lower temperatures, and in parallel with this the high temperature peaks $\left(\alpha_{2}\right.$ and $\left.\alpha_{3}\right)$ developed. Their $T_{\max }$ seemed to 


\section{Product distribution}
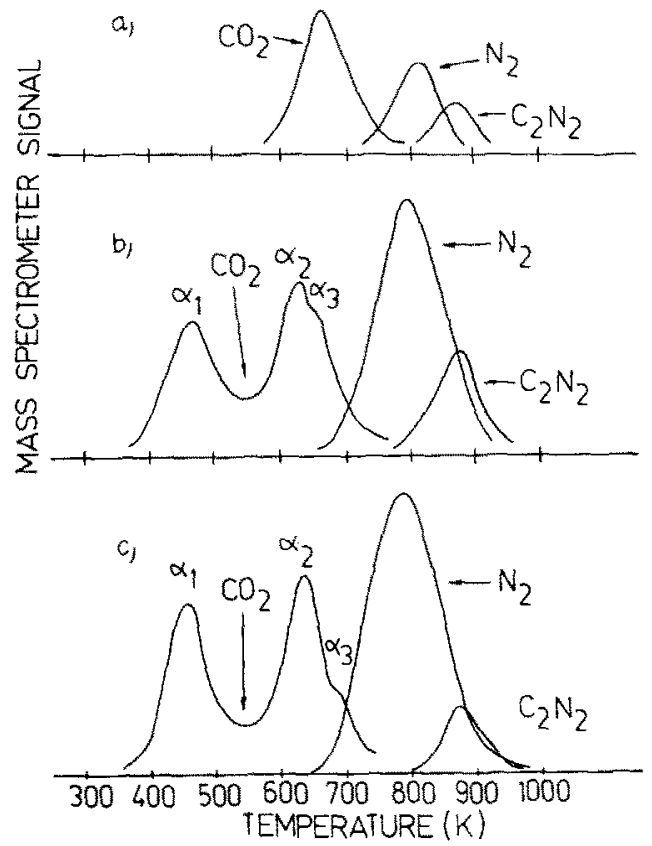

Fig. 7. Temperature programmed desorption spectra following $\mathrm{HNCO}$ adsorption at $300 \mathrm{~K}$ on a Cu(111) surface predosed with (a) $1.2 \mathrm{~L} \mathrm{O}_{2}$, (b) $60 \mathrm{~L} \mathrm{O}_{2}$, (c) $1700 \mathrm{~L} \mathrm{O}_{2}$ at $300 \mathrm{~K}$. The $\mathrm{HNCO}$ exposure was $90 \mathrm{~L}$. The curves are uncorrected for detection sensitivities.

be independent of the coverage. The kinetic data calculated by the different methods are listed in table 2 .

The peak temperature for the nitrogen signal was $793-803 \mathrm{~K}$; it showed very

Table 1

The effect of oxygen coverage on the $\mathrm{CO}_{2}$ signal and on the ratios of signals of products (TPD measurements)

\begin{tabular}{llll} 
& $\begin{array}{l}h_{\mathrm{O}} / h_{\mathrm{Cu}}=0.018, \\
\theta \sim 0.02\end{array}$ & $\begin{array}{l}h_{\mathrm{O}} / h_{\mathrm{Cu}}=0.17, \\
\theta \sim 0.17\end{array}$ & $\begin{array}{l}h_{\mathrm{O}} / h_{\mathrm{Cu}}=0.35, \\
\theta \sim 0.35\end{array}$ \\
\hline $\mathrm{CO}_{2}$ & 0.51 & 1.30 & 1.43 \\
$\mathrm{CO}_{2} / \mathrm{C}_{2} \mathrm{~N}_{2}$ & 3.1 & 4.0 & 5.9 \\
$\mathrm{~N}_{2} / \mathrm{C}_{2} \mathrm{~N}_{2}$ & 2.5 & 3.5 & 5.7 \\
$\mathrm{~N}_{2} / \mathrm{CO}_{2}$ & 0.80 & 0.78 & 0.87
\end{tabular}

The above values are not corrected for detection sensitivities. 
Table 2

Summary of the results observed for the decomposition of surface isocyanate on oxygencovered $\mathrm{Cu}(111)$ face

\begin{tabular}{llllll}
\hline State & $\begin{array}{l}T_{\mathrm{p}} \\
(\mathrm{K})\end{array}$ & $\begin{array}{l}E^{\mathrm{b}} \\
(\mathrm{kJ} / \mathrm{mol})\end{array}$ & $\begin{array}{l}k_{0}^{\mathrm{b}} \\
\left(\mathrm{s}^{-1}\right)\end{array}$ & $\begin{array}{l}E^{\mathrm{c}} \\
(\mathrm{kJ} / \mathrm{mol})\end{array}$ & $\begin{array}{l}k_{0}^{\mathrm{c}} \\
\left(\mathrm{s}^{-1}\right)\end{array}$ \\
\hline $\mathrm{CO}_{2}\left(\alpha_{1}\right) / \mathrm{HNCO}$ & $513-463$ & 46.0 & & 66.0 & \\
$\mathrm{CO}_{2}\left(\alpha_{2}\right) / \mathrm{HNCO}$ & 633 & 82.9 & $7 \times 10^{5}$ & 98.0 & $1.2 \times 10^{7}$ \\
$\mathrm{~N}_{2} / \mathrm{HNCO}$ & 793 & 146.5 & $5.1 \times 10^{9}$ & & \\
$\mathrm{C}_{2} \mathrm{~N}_{2} / \mathrm{HNCO}$ & 874 & 169.8 & $4 \times 10^{11}$ & 158.3 & $1.4 \times 10^{9}$ \\
\hline
\end{tabular}

a The notation of $\mathrm{A}(\alpha) / \mathrm{B}$ refers to the $\alpha$ state or desorption peak for gas $\mathrm{A}$ following adsorption of gas $\mathbf{B}$.

${ }^{b}$ Calculated on base of heating rate variation method [11].

${ }^{\mathrm{c}}$ Calculated according to approximation method of Chan et al. [12].

little variation with the coverage (fig. 8). The activation energy for the desorption of nitrogen $(146.5 \mathrm{~kJ} / \mathrm{mol})$ was considerably higher than that for $\mathrm{CO}_{2}$ evolution. The desorption maximum of $\mathrm{C}_{2} \mathrm{~N}_{2}$ occurred at $874 \mathrm{~K}$; it showed no dependence on the HNCO coverage (fig. 8). We obtained $169.8 \mathrm{~kJ} / \mathrm{mol}$ for the activation energy for $\mathrm{C}_{2} \mathrm{~N}_{2}$ formation (table 2).

The Auger spectra of the sample covered with HNCO and heated to different temperatures are in good agreement with the results of TPD measurements. No decrease in the $\mathrm{N}$ signal was experienced below $700 \mathrm{~K}$. Decreases in the $\mathrm{C}$ and $\mathrm{O}$ signals were observed above $400 \mathrm{~K}$. In the final stage, above $750 \mathrm{~K}$, only the signals

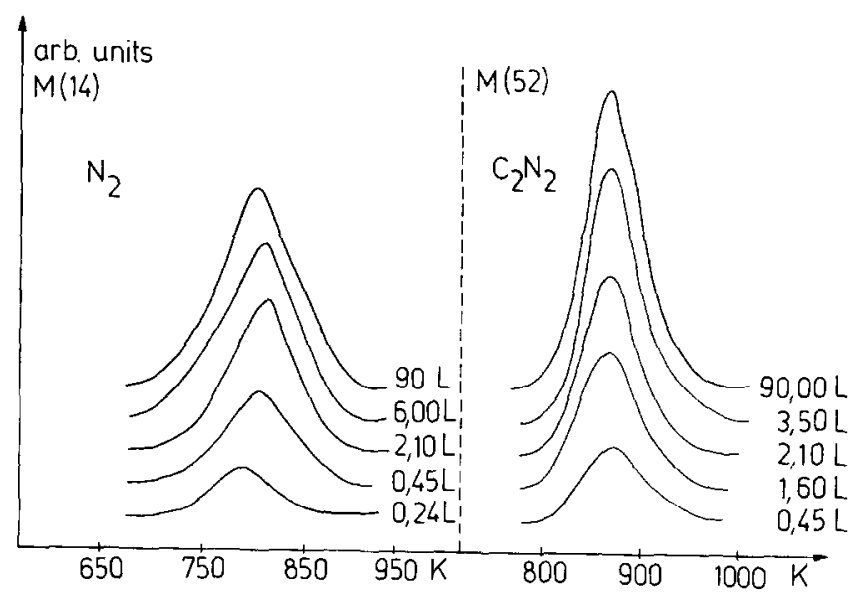

Fig. 8. Nitrogen (14 amu) and $\mathrm{C}_{2} \mathrm{~N}_{2}(52 \mathrm{amu})$ desorption spectra subsequent to the adsorption of $\mathrm{HNCO}$ on $\mathrm{Cu}(111)$ at $300 \mathrm{~K}$. The $\mathrm{Cu}(111)$ surface was predosed with $60 \mathrm{~L} \mathrm{O}_{2}(\theta \sim 0.17)$ at $300 \mathrm{~K}$. 
due to $\mathrm{C}$ and $\mathrm{N}$ were detected, and these were eliminated together on further heating.

\subsection{Electron energy loss studies}

EELS provide a good picture of the electronic structures of the clean metal and the metal-gas system. From the point of view of gas adsorption and surface contamination, the surface plasmon losses are important. As the adsorption of gases mainly influences the losses due to surface plasmon, the effect of gas adsorption may help in differentiating between bulk and surface losses.

We first determined the dependence of the elastic peak height reflected from a clean $\mathrm{Cu}(111)$ surface on the primary energy at $20-125 \mathrm{eV}$. The maximum of the reflectance appeared at $70 \mathrm{eV}$, in good agreement with the results of Kessler and Thieme [13]. Further measurements were performed at a primary electron energy of $70 \mathrm{eV}$. In this case the beam current was $0.2 \mu \mathrm{A}$.

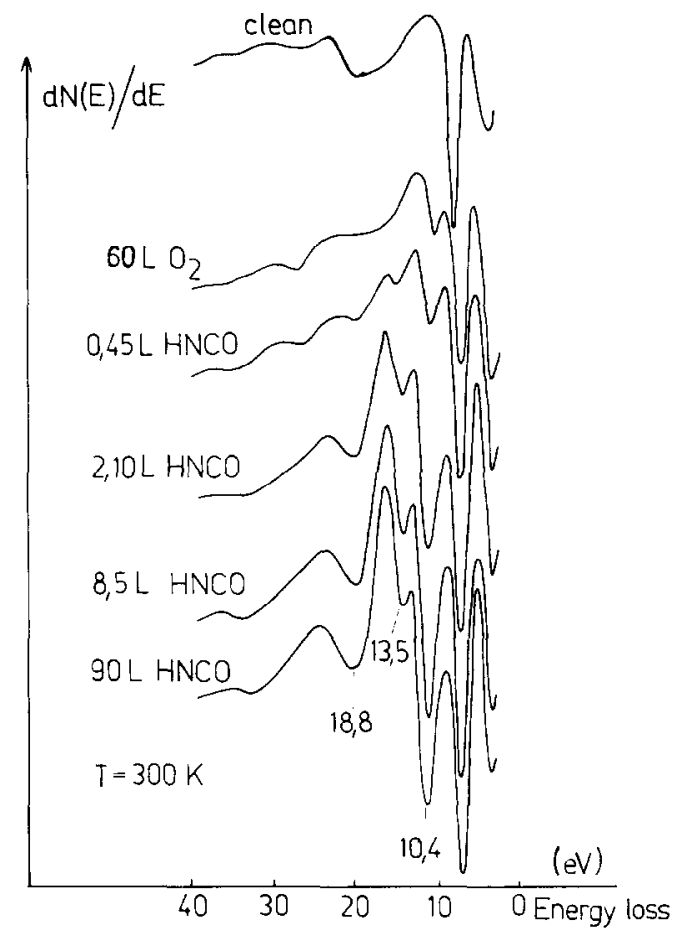

Fig. 9. Electron energy loss spectra of $\mathrm{Cu}(111)$ surface covered with oxygen $(\theta \approx 0.17)$ as a function of $\mathrm{HNCO}$ exposition. For comparison, the ELS of clean Cu(111) surface is also shown $\left(E_{\mathrm{p}}=70 \mathrm{eV}, I=0.2 \mu \mathrm{A}\right)$. 
The characteristic loss energies of a $\mathrm{Cu}(111)$ surface appeared at 2.7, 4.8, 7.1, 18.8 and $26 \mathrm{eV}$. These losses did not vary with the primary electron energy. Admission of oxygen onto the surface $\left(60 \mathrm{~L}\right.$, at $10^{-8}$ Torr) enhanced the intensity of the elastic peak and that of the $2.7 \mathrm{eV}$ peak, and markedly reduced the intensity of the peak at $18.8 \mathrm{eV}$. The peak at $7.1 \mathrm{eV}$ was shifted to $6.5 \mathrm{eV}$. At $9.3 \mathrm{eV}$ a new loss appeared (fig. 9).

The introduction of $\mathrm{HNCO}$ onto a $\mathrm{Cu}(111)$ surface predosed with $60 \mathrm{~L} \mathrm{O}_{2}$ at $300 \mathrm{~K}$, produced new intensive loss peaks at 10.4 and $13.5 \mathrm{eV}$ (fig. 9). The intensities of these peaks at 10.4 and $13.5 \mathrm{eV}$, and also that of the elastic peak, increased up to an exposure of $10 \mathrm{~L} \mathrm{HNCO}$. At the same time the intensity of the peak at $9.3 \mathrm{eV}$, developed due to the adsorption of oxygen, decreased and appeared as a shoulder. It should also be noted that the intensity of the peak at $18.8 \mathrm{eV}$, which decreased following the adsorption of oxygen, became higher upon the introduction of $\mathrm{HNCO}$, and at $10 \mathrm{~L}$ reached its original value.

The electron energy loss spectra were also taken after heating the sample exposed to $90 \mathrm{~L}$ HNCO to different temperatures. Spectra are shown in fig. 10.

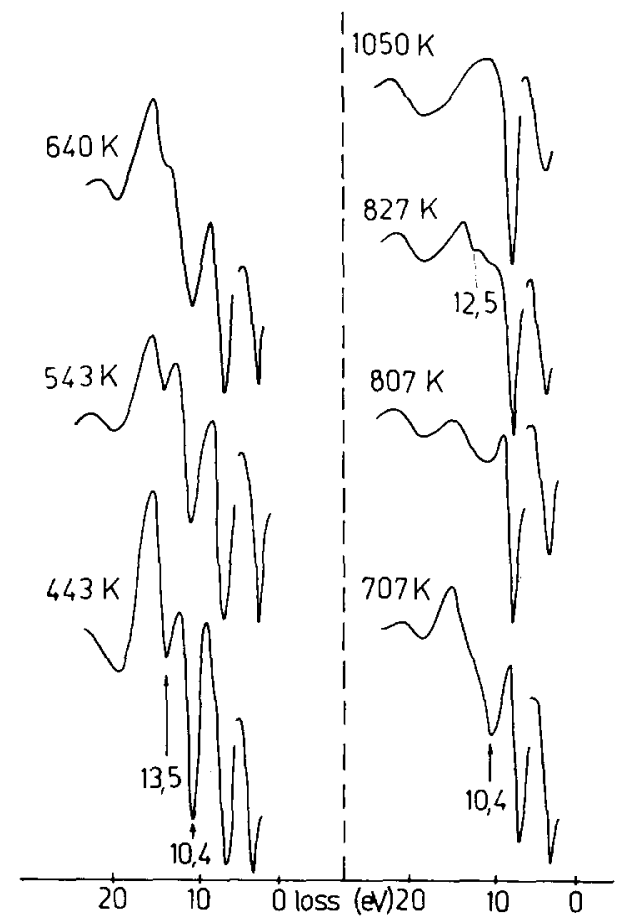

Fig. 10. Electron energy loss spectra taken after heating the sample exposed to $90 \mathrm{~L}$ HNCO to different temperatures. Heating rate was $10 \mathrm{~K} \mathrm{~s}^{-1}$. 


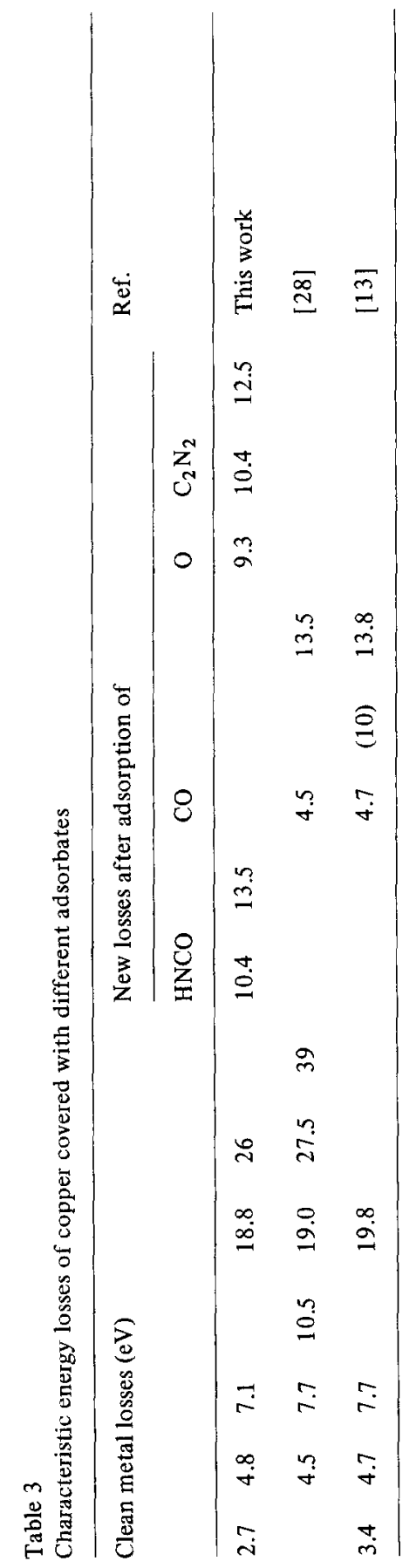


Heating the sample exposed to HNCO to above $443 \mathrm{~K}$ decreased the intensities of both the 10.4 and the $13.5 \mathrm{eV}$ peaks. The $13.5 \mathrm{eV}$ peak disappeared at 650 $707 \mathrm{~K}$. The peak at $10.4 \mathrm{eV}$ was more stable. It was present up to $874 \mathrm{~K}$. A new feature of the spectrum was that above $707 \mathrm{~K}$ a shoulder appeared at $12.6 \mathrm{eV}$. This was eliminated only above $874 \mathrm{~K}$.

Exposure of the clean and oxidized $\mathrm{Cu}(111)$ surface to $100 \mathrm{~L} \mathrm{CO}, \mathrm{CO}_{2}$ and activated nitrogen at $300 \mathrm{~K}$ caused no change in the electron energy loss spectra.

Table 3 gives the loss energies observed in the present work, together with some data from the literature for comparison.

\section{Discussion}

The adsorption of HNCO was earlier investigated on $\mathrm{Pt}(110)$ and $\operatorname{Pt}(111)$ surfaces [14]. In contrast to these surfaces, no adsorption of HNCO was observed on a clean $\mathrm{Cu}(111)$ surface at $300 \mathrm{~K}$. The presence of adsorbed oxygen, however, exerted a dramatic influence on the adsorptive properties of this surface and caused $\mathrm{HNCO}$ adsorption. Based on the $\mathrm{N}$ and $\mathrm{C}$ signals in the Auger spectra, the adsorption of $\mathrm{HNCO}$ increased linearly with the extent of the surface concentration of oxygen up to $\sim 0.05$ coverage (fig. 6 ). The saturation coverage of HNCO was calculated to be $(9.5 \pm 0.5) \times 10^{13}$ at $300 \mathrm{~K}$. This calculation was based on the relationship found between the ratio $h_{\mathrm{N}} / h_{\mathrm{Cu}}$ in the Auger spectra and the nitrogen coverage in the study of the adsorption of atomic nitrogen on $\mathrm{Cu}(111)$ surface [26]. The initial sticking probability for the adsorption of $\mathrm{HNCO}$, determined from the change of the $\mathrm{N}$ signal on the Auger spectra (fig. 4), is 0.11 .

The marked influence of oxygen adsorbed on $\mathrm{Cu}(110)$ on the subsequent adsorption of $\mathrm{CH}_{3} \mathrm{OH}, \mathrm{C}_{2} \mathrm{H}_{5} \mathrm{OH}, \mathrm{HCHO}$ and $\mathrm{HCOOH}$ has been nicely demonstrated by Madix et al. [15]. Recently the interaction of oxygen chemisorbed on a $\mathrm{Cu}(100)$ surface with alcohols was investigated by means of high rcsolution clcctron cncrgy loss spectroscopy, and $\mathrm{CH}_{3} \mathrm{O}-\mathrm{Cu}$ and $\mathrm{C}_{2} \mathrm{H}_{5} \mathrm{O}-\mathrm{Cu}$ stable surface species were identified [16].

Before attempting a discussion of the results, we should deal briefly with the $\mathrm{Cu}-$ $\mathrm{O}_{2}$ interaction. The adsorption of $\mathrm{O}_{2}$ on a $\mathrm{Cu}(111)$ surface has been less extensively investigated than on other $\mathrm{Cu}$ surfaces. No ordered superstructure was observed in LEED studies [17-20]. Bootsma et al. [7] recently examined the interactions of $\mathrm{O}_{2}$ and $\mathrm{N}_{2} \mathrm{O}$ in the low temperature range with a $\mathrm{Cu}(111)$ surface by ellipsometry, Auger electron spectroscopy and LEED. They found that $\mathrm{O}_{2}$ chemisorbed dissociatively, with an initial sticking probability of about $10^{-3}$ and an apparent activation energy of $9-16 \mathrm{~kJ} / \mathrm{mol}$. The oxygen coverage was maximum at $\theta=0.45 \pm 0.05$. The LEED patterns indicated that the adsorption takes place in a disordered, random fashion. 


\subsection{Interaction of adsorbed oxygen with HNCO}

A possible role of the adsorbed oxygen in causing the adsorption of HNCO on copper is to promote the dissociative adsorption of HNCO. This may occur through the following transition state

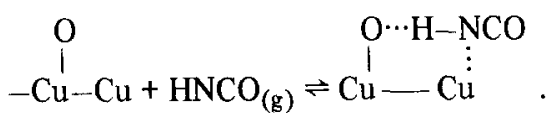

The hydrogen is then bonded to adsorbed oxygen, while NCO is adsorbed on an adjacent vacant adsorption site:

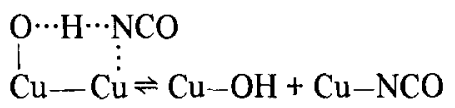

In the light of the results of IR spectroscopic measurements [1-6] we assume that $\mathrm{NCO}$ is bonded to the metal via the nitrogen end of the molecule.

The adsorption of $\mathrm{HNCO}$ was accompanied by the evolution of water, indicating that the dehydration of the surface

$\mathrm{Cu} \mathrm{OH}+\mathrm{Cu}-\mathrm{OH} \rightarrow \mathrm{Cu}-\mathrm{O}+\mathrm{Cu}+\mathrm{H}_{2} \mathrm{O}_{(\mathrm{g})}$,

or

$\mathrm{Cu}-\mathrm{OH}+\mathrm{HNCO}_{(\mathrm{g})}+\mathrm{Cu} \rightarrow \mathrm{Cu}+\mathrm{H}_{2} \mathrm{O}_{(\mathrm{g})}+\mathrm{Cu}-\mathrm{NCO}$,

occurred rapidly and simultaneously with the adsorption. This process was practically complete at $300 \mathrm{~K}$, as neither $\mathrm{H}_{2} \mathrm{O}$ nor hydrogenated products were found in the desorbing products. This result is in harmony with the observations of Roberts et al. [21] on the stability of $\mathrm{OH}$ groups on $\mathrm{Cu}(111)$ surface. As we could not identify either $\mathrm{HNCO}, \mathrm{NCO}$ or $(\mathrm{NCO})_{2}$ in the desorhing gases, we may infer that $\mathrm{NCO}$ is strongly bonded to the $\mathrm{Cu}$ and does not desorb as such. With the increase of the temperature, $\mathrm{CO}_{2}$ evolution was first observed, showing that reactions occurred in the adsorbed phase. It is very likely that adsorbed $\mathrm{NCO}$ groups reacted with adsorbed oxygen on the neighbouring site and that $\mathrm{CO}_{2}$ desorbed:

$\mathrm{Cu}-\mathrm{NCO}+\mathrm{Cu}-\mathrm{O} \rightarrow \mathrm{Cu}-\mathrm{N}+\mathrm{Cu}+\mathrm{CO}_{2(\mathrm{~g})}$.

An alternative explanation for these results is that $\mathrm{NCO}$ is also dissociated on the copper surface during the adsorption at $300 \mathrm{~K}$ :

$\mathrm{Cu}-\mathrm{NCO}+\mathrm{Cu}$ (or $\mathrm{Cu}-\mathrm{O}) \rightarrow \mathrm{Cu}-\mathrm{N}+\mathrm{Cu}-\mathrm{CO}\left(\right.$ or $\left.\mathrm{Cu}-\mathrm{CO}_{2}\right)$.

This process probably occurs on $\mathrm{Pt}$ surfaces [14]. The adsorption behaviour of $\mathrm{CO}$ and $\mathrm{CO}_{2}$ on copper surfaces, however, make this explanation very unlikely. No, or only an extremely small interaction of these molecules with a clean $\mathrm{Cu}(111)$ surface was detected at $300 \mathrm{~K}$ in the present work. The adsorption of $\mathrm{CO}$ on a clean 
$\mathrm{Cu}(111)$ surface was observed only at low temperature, at $140 \mathrm{~K}[13,22-24]$. It gave a $\sqrt{3} \times \sqrt{ } 3$ R30 $0^{\circ}$ LEED pattern [24]. It could be pumped off around $170 \mathrm{~K}$. From this result an adsorption energy of about $50 \mathrm{~kJ} / \mathrm{mol}$ was estimated. Work function changes during desorption of $\mathrm{CO}$ also indicated that $\mathrm{CO}$ desorbed completely around $190 \mathrm{~K}$ [13].

One may argue that the surface oxygen on the copper increases the sticking coefficient and the adsorption of $\mathrm{CO}$ and $\mathrm{CO}_{2}$. However, we could not detect the adsorption of $\mathrm{CO}$ or $\mathrm{CO}_{2}$ on a partially oxidized $\mathrm{Cu}(111)$ surface at $300 \mathrm{~K}$. This is in harmony with the experimental finding of Wachs and Madix [25] on a $\mathrm{Cu}(110)$ surface. From a comparison of the adsorption characteristics of $\mathrm{CO}$ and $\mathrm{CO}_{2}$ on clean and partially oxidized surfaces at $180 \mathrm{~K}$, they found that the total amount of $\mathrm{CO}$ and $\mathrm{CO}_{2}$ adsorbed decreased following initial exposure to oxygen. The presence of oxygen atoms on the copper surface diminished the sticking probabilities of $\mathrm{CO}$ and $\mathrm{CO}_{2}$; this is very probably due to the decreased number of adsorption sites available to the $\mathrm{CO}$ and $\mathrm{CO}_{2}$.

Accordingly, we may conclude that NCO exists as such on a $\mathrm{Cu}(111)$ surface.

We note that our recent infrared spectroscopic measurements on the stability of NCO species on partially oxidized copper, provide additional evidence for the existence of $\mathrm{NCO}$ on $\mathrm{Cu}$ in a moderate temperature range. The adsorption of $\mathrm{HNCO}$ on $\mathrm{Cu} / \mathrm{SiO}_{2}$ produced a band at $2210 \mathrm{~cm}^{-1}$, which can be attributed to $\mathrm{Cu}-\mathrm{NCO}$. The location of this band agrees well with that observed in the $\mathrm{NO}+\mathrm{CO}$ reaction on a $\mathrm{CuO} / \mathrm{SiO}_{2}$ catalyst [2]. The assignment of this band is confirmed by the IR spectra of $\mathrm{Cu}(\mathrm{NCO})_{2}$. The intensity of the $2210 \mathrm{~cm}^{-1}$ band started to decrease above $403 \mathrm{~K}$, and it disappeared completely above $600 \mathrm{~K}$.

The fact that $\mathrm{CO}_{2}$ desorbed in two main stages can be explained by the assumption that - from the point of view of reactivity - two different kinds of adsorbed oxygen (or adsorbed $\mathrm{HNCO}$ ) exist on the surface. In our opinion the most probable reason for the two stages is that in the low temperature stage $\mathrm{NCO}$ reacts with the adjacent adsorbed $\mathrm{O}$ in a second order process, while migration of the reactants is necessary for the second stage of the reaction, which requires somewhat higher activation energy. The relatively low activation energies and preexponential factor of the $\mathrm{CO}_{2}$ evolution seem to be in harmony with this consideration.

The nitrogen formed in the surface reaction of the NCO species remains bonded to the copper; it desorbs above $700 \mathrm{~K}$ with an activation energy of $146.5 \mathrm{~kJ} / \mathrm{mol}$. Accurate determination of the ratio of the signals at 28 and 14 amu indicate that nitrogen atoms recombine before desorption. We have recently studied the interaction of atomic $\mathrm{N}$ on a $\mathrm{Cu}(111)$ surface [26]. The peak temperature and the activation energy for the desorption of nitrogen agreed very well with the data obtained in this work.

A surprising result of the thermal desorption measurements was the identification of $\mathrm{C}_{2} \mathrm{~N}_{2}$ in the desorbing gases. It was the most stable surface compound, desorbing only above $800 \mathrm{~K}$. The fact that the relative amount of $\mathrm{C}_{2} \mathrm{~N}_{2}$ increased 
with the decrease of the 0 coverage may suggest that it is formed mainly after the consumption of surface oxygen in reaction (2). We may assume that in this stage the process occurs

$\mathrm{Cu}-\mathrm{NCO}+\mathrm{Cu} \rightarrow \mathrm{Cu}-\mathrm{NC}+\mathrm{Cu}-\mathrm{O}$.

As we could not detect $\mathrm{CN}$ radicals in gas phase we may assume that $\mathrm{CN}$ groups recombined before desorption. The desorption characteristics of $\mathrm{C}_{2} \mathrm{~N}_{2}$ agreed with those determined in a separate study of the interaction of $\mathrm{C}_{2} \mathrm{~N}_{2}$ with $\mathrm{Cu}(111)$ [27]. $\left(\mathrm{C}_{2} \mathrm{~N}_{2}\right.$ desorbed in one stage; $T_{\max }$ was $860 \mathrm{~K}$. No desorption of $\mathrm{CN}(26 \mathrm{amu})$ was observed. The value of the activation energy for the desorption of $\mathrm{C}_{2} \mathrm{~N}_{2}$ was $160 \mathrm{~kJ} / \mathrm{mol}$.)

\subsection{Electron energy loss spectra}

EEL spectra provide further evidences for the proposed model of HNCO adsorption and reactions. Before attempting to discuss the losses due to $\mathrm{HNCO}$ adsorption, it is instructive to summarize the previous results obtained for $\mathrm{CO}$ adsorption on copper surfaces.

The adsorption of $\mathrm{CO}$ on a $\mathrm{Cu}(311)$ surface at $77 \mathrm{~K}$ caused two strong maxima, at 4.5 and $13.5 \mathrm{eV}$, and the disappearance of copper losses at 7.7 and $19 \mathrm{eV} \mathrm{[28].}$ The small loss peak at $10.5 \mathrm{eV}$ was also removed by $\mathrm{CO}$ adsorption. On warming of the crystal to room temperature, the loss spectrum of the clean surface was always recovered, indicating the total desorption of $\mathrm{CO}$, as found by surface potential measurements [29].

Kessler and Thieme [13] observed a decrease in the intensities of the 4.7 and $7.7 \mathrm{eV}$ peaks due to the adsorption of $\mathrm{CO}$ on a $\mathrm{Cu}(111)$ surface at $150 \mathrm{~K}$. A new loss peak was produced at $13.8 \mathrm{eV}$, and also a small one at $10 \mathrm{eV}$. The $10 \mathrm{eV}$ peak was stable up to $450 \mathrm{~K}$ and was attributed to adsorbed oxygen, which was assumed to be produced by the dissociation of $\mathrm{CO}$ in the electron beam.

Our results showed that the adsorption of oxygen also influenced the $7.1 \mathrm{eV}$ loss, indicating that this loss is probably due to surface plasmon [30,31] and not to bulk plasmon [32-34]. The fact that the adsorption of oxygen also decreased the loss at $18.8 \mathrm{eV}$, similarly as in the adsorption of $\mathrm{CO}$ at low temperature [28], may support the idea of Wehenkel [35] that, in contrast to the former interpretation $[30,33,34]$, the losses bclow $35 \mathrm{eV}$ are largely of a hybrid character, containing both a surface and a bulk contribution; the surface contribution is stronger below $10 \mathrm{eV}$. A new loss appeared at $9.3 \mathrm{eV}$, which may confirm the interpretation of Kessler and Thieme [13] for the origin of the $10 \mathrm{eV}$ loss in their spectra.

The adsorption of HNCO at $300 \mathrm{~K}$ caused two strong new losses, at 10.4 and $13.5 \mathrm{eV}$. In addition, the intensity of the peak at $18.8 \mathrm{eV}$, which greatly decreased on the adsurption of oxygen, was recovered; this clearly demonstrated the occurrence of a reaction between adsorbed oxygen and HNCO. The loss at $9.3 \mathrm{eV}$ caused by the adsorption of oxygen appears as a shoulder at low exposure of $\mathrm{HNCO}$; at 
higher exposures it can not be discerned, partly due to the large peak at $10.4 \mathrm{eV}$, but, in our opinion, mainly due to the reaction between adsorbed oxygen and HNCO.

As adsorbed $\mathrm{CO}$ produced a loss at $13.5-13.8 \mathrm{eV}$, it would be tempting to attribute the $13.5 \mathrm{eV}$ loss to the adsorbed $\mathrm{CO}$ formed in the dissociation of NCO. We believe, however, that the arguments mentioned previously against the existence of $\mathrm{CO}$ on the surface are strong enough to exclude this possibility. In addition, we did not find the strong loss at $4.5 \mathrm{eV}$ observed by Papp [28] during $\mathrm{CO}$ adsorption at $140 \mathrm{~K}$, which was larger than the $13.5 \mathrm{eV}$ feature, but we identified a new loss at $10.4 \mathrm{eV}$.

Accordingly, we may attribute these losses to the adsorbed NCO. Unfortunately, as regards the electron structure and levels of NCO very little is known which may be of help in the interpretation of these losses. The fact that the highest energy $\mathrm{NCO}$ loss feature is close to that of adsorbed $\mathrm{CO}$ on different metals makes it likely that the same electron transition occurs in the present case, too.

Heating the sample exposed to $\mathrm{HNCO}$ upto $650-707 \mathrm{~K}$ caused the disappearance of the peak at $13.5 \mathrm{eV}$ and the appearance of a shoulder at $12.6 \mathrm{eV}$. Taking into account the results of the thermal desorption measurements, it seemed very likely that formation of the cyanide group is responsible for the appearance of this new loss. Our recent ELS measurements seem to prove this assumption. Adsorption of $\mathrm{C}_{2} \mathrm{~N}_{2}(0.36 \mathrm{~L})$ on a clean $\mathrm{Cu}(111)$ surface produced a loss at $12.6 \mathrm{eV}$. With the increase of the $\mathrm{C}_{2} \mathrm{~N}_{2}$ exposure this peak became larger, and a strong peak also developed at $10.3 \mathrm{eV}[27]$.

\section{References}

[1] M.L. Unland, J. Catalysis 31 (1973) 459.

[2] I.W. London and A.T. Rell, I. Catalysis 31 (1973) 96.

[3] F. Solymosi, L. Völgyesi and J. Raskó, Z. Physik. Chem. (NF) 120 (1980) 79, and references therein.

[4] F. Solymosi, J. Kiss and J. Sárkány, in: Proc. 7th Intern. Vacuum Congr. and 3rd Intern. Conf. on Solid Surfaces, Eds. R. Dobrozemsky et al. (Vienna, 1977) p. 819.

[5] F. Solymosi, L. Völgyesi and J. Sárkány, J. Catalysis 55 (1978) 336.

[6] F. Solymosi and T. Bánsági, J. Phys. Chem. 83 (1979) 552.

[7] F.H.P.M. Habraken, E.P. Kieffer and G.A. Bootsma, Surface Sci. 83 (1979) 45.

[8] M.P. Hooker and J.T. Grant, Surface Sci. 62 (1977) 21;

J.T. Grant and M.P. Hooker, Solid State Commun. 19 (1976) 111.

[9] J.G. MoCarty and R.J. Madix, J. Catalysis 48 (1977) 422.

[10] E. Umbach, J.C. Fuggle and D. Menzel, J. Electron Spectrosc. 10 (1977) 15.

[11] P.A. Redhead, Vacuum 12 (1962) 203.

[12] C.M. Chan, R. Aris and W.H. Weinberg, Appl. Surface Sci. 1 (1978) 360, 377.

[13] J. Kessler and F. Thieme, Surface Sci. 67 (1977) 405.

[14] F. Solymosi and J. Kiss, submitted for publication.

[15] R.J. Madix, Surface Sci. 89 (1979) 540. 
[16] B.A. Sexton, Surface Sci. 88 (1979) 299.

[17] G. Ertl, Surface Sci. 6 (1967) 208.

[18] G.W. Simmons, D.F. Mitchell and K.R. Lawless, Surface Sci. 8 (1967) 130.

[19] A. Oustry, L. Lafourcade and A. Escaut, Surface Sci. 40 (1973) 545.

[20] L. McDonnell and D.P. Woodruff, Surface Sci. 46 (1974) 505.

[21] Chak-tong Au, J. Breza and M.W. Roberts, Chem. Phys. Letters 66 (1979) 340.

[22] G. Ertl, Surface Sci. 7 (1967) 309.

[23] J. Pritchard, J. Vacuum Sci. Technol. 9 (1972) 895.

[24] H. Conrad, G. Ertl, J. Küppers and E.E. Latta, Solid State Commun. 17 (1975) 613.

[25] J.E. Wachs and R.J. Madix, J. Cataly sis 53 (1978) 208.

[26] J. Kiss, A. Berkó and F. Solymosi, in: Proc. 8th Intern. Vacuum Congr. and 4th Intern. Conf. on Solid Surfaces, Cannes, 1980, Vol. I, p. 521.

[27] F. Solymosi and J. Kiss, unpublished results.

[28] 11. Papp, Surface Sci. 63 (1977) 182.

[29] H. Papp and J. Pritchard, Surface Sci. 53 (1975) 371.

[30] L.K. Jordan and E.J. Scheibner, Surface Sci. 10 (1968) 373.

[31] A.R.L. Moss and B.H. Blott, Surface Sci. 17 (1969) 240.

[32] J. Daniels, C.V. Festenberg, H. Raether and K. Zeppenfeld, Springer Tracts in Modern Physics 54 (1970) 77.

[33] H. Ehrenreich and H.R. Phillip, Phys, Rev. 128 (1962) 1622.

[34] I. Marklund, S. Andersun and J. Martinson, Arkiv Fysik 37 (1968) 127.

[35] C. Wehenkel, J. Physique 36 (1975) 199. 